\title{
GENETICS OF FEMALE DIMORPHISM IN ISCHNURA DEMORSA
}

\author{
CLIFFORD JOHNSON \\ Department of Biology, New Mexico Institute of Mining and Technology, Socorro, New Mexico
}

Received 13.xii. $6_{5}$

\section{INTRODUCTION}

Sex-Controlled female dimorphism of many small damselflies, especially evident in the genus Ischnura, offers an excellent trait for analysing selection and adaptation in natural populations. One female morph, the andromorph, has the male colour pattern of its species whereas the second morph, the heteromorph, is distinct; however, it is similar in pattern with the comparable morph in several other species of Ischnura. The first stage of this study was given in the analysis of female dimorphism of Ischnura damula by Johnson ( $1964 a$ ). The present report gives results of breeding tests on a second species, Ischnura demorsa, sympatric with damula and, unlike the latter, exhibiting marked colour changes with age.

In evolutionary studies involving such species, a knowledge of the trait's heritability in different environments and an ability to discriminate between genetic and age-induced variation must exist in addition to an understanding of the inheritance mechanism.

\section{MATERIALS AND METHODS}

Effects of age and environment on morph expression have been observed under constant laboratory environments and in populations existing under marked ecological differences. Constant laboratory conditions were obtained with a Percival Plant Growth Environmental Chamber, Model PGC- 78 using an illumination intensity of approximately 850 lumen.

All breeding stocks were collected from the Bosque Del Apache National Wildlife Refuge 16 miles south of Socorro. Procedures for laboratory mating and culture are given in detail by Johnson (1965). A total of 23 crosses were obtained in the interval between 1962 and 1965 . The breeding tests consist of mating virgin females involving two distinct phenotypes with males available in only one phenotypic class. Virgin females were obtained by collecting late instar larvae in the field and rearing through emergence in the laboratory. Each female was mated once; however, multiple matings by males were made where possible especially involving both female morphs.

All progency were reared to the stage where definite sex determination was possible and male offspring were then discarded to accommodate increased demands required of growing females. At the time, males were not suspected of expressing variation correlated with the female dimorphism. All female offspring were scored for morph type shortly after emergence and discarded.

\section{EFFECTS OF AGE AND ENVIRONMENT}

Colour patterns in both female morphs of $I$. demorsa change during the interval between emergence and maturity. The change is due to 
additional pigment and deposition of an exudate, pruinesence, producing a final appearance similar for both morphs.

The two dimorphic forms are clearly expressed within 20 minutes following adult emergence at $20^{\circ} \mathrm{C}$. The morph differences are best expressed on the dorsal synthorax. The pattern of black mid-dorsal and humeral stripes is similar for males and both female morphs. The light-coloured regions between the dark stripes and lateral to the humeral stripes are pale green in males and andromorphic females. This colour pattern is retained throughout life for the males. The comparable regions on the heteromorphic females are orange in colour. As the females mature, these basic patterns become obscured in a different sequence for each morph. The andromorphic females develop black pigment in the regions between the mid-dorsal and humeral stripes culminating in a solid black metallic dorsum on the synthorax. In this colour phase andromorphic females are distinct from males and heteromorphic females. It is interesting to note that matings with such females were only successful while they were in this phase. Deposition of pruinescence follows producing a patternless bluish-white colour over the entire body. Heteromorphic females develop only traces of additional black pigment and the metallic attribute present in andromorphic females is absent. Heteromorphic females will mate at any stage of this develpoment. Deposition of pruinescence follows producing the same effect observed in andromorphic females. Neither morph mates after onset of pruinesence. These changes are illustrated in fig. I. Application of acetone to the synthorax's pruinesence-cover allows determination of morph type in later life.

The study of $I$. damula involved a species with distinct female morphs unobscured by aging (Johnson, $1964 a$ ). In that study, samples from populations having distinct frequencies of the two morphs were raised under similar laboratory environments. Morph frequencies characteristic for their parental population were obtained on emergence. In addition the frequencies in natural populations were followed through consecutive generations including both summer and winter seasons. These data did not indicate any environmental influence on morph expression. In another study involving damselfly polymorphism, the data did not reveal an environmental influence (Johnson, $1964 b$ ). Consequently, time-consuming laboratory cultures for heritability data were deleted for $I$. demorsa. Data on morph frequencies over consecutive generations in populations existing under marked ecological differences are available also supporting the assumption that the dimorphism is a genetic expression with high heritability. These data will be presented fully in a subsequent report.

Data reflecting environmental influence on age-induced colour variation are shown in table $\mathrm{I}$. The duration in each phase is apparently shorter at higher temperatures as is total life. The life durations shown in table $I$ are shorter than an interval of 34 days reported in a laboratory colony of Ischnura verticalis by Grieve (1937). 
The time required to reach the pruinescene phase should however approximate the minimal age of bluish-white individuals for a given mean temperature. It should be noted that all colour stages develop in both virgin and mated females.

\section{ANDROMORPHIC}
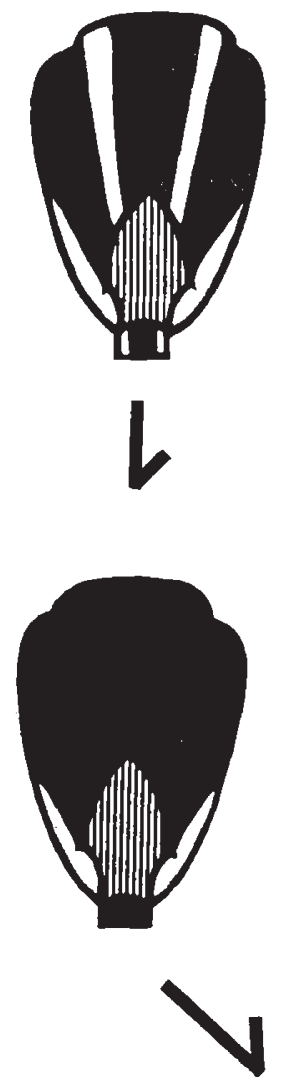

\section{HETEROMORPHIC}
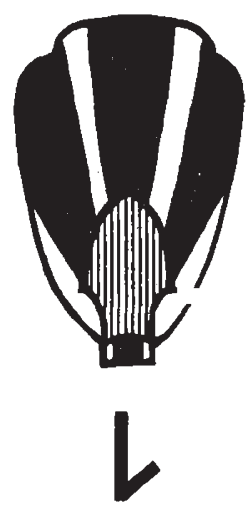

2
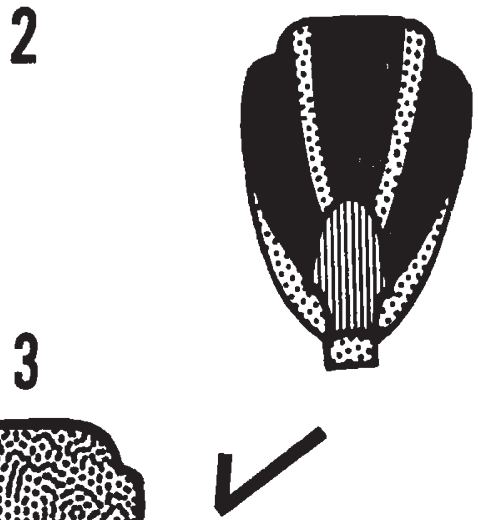

Frg. 1.-Variation with age on the dorsal synthorax of female morphs in Ischnura demorsa. Light-coloured regions of phase 1 are pale green and orange in andromorphs and heteromorphs respectively. Phase 2 of the andromorph is metallic black. Phase 3 is a patternless bluish-white colour in both morphs.

\section{BREEDING RESULTS}

Observations reported in the study of $I$. damula indicated the validity of classifying the trait as sex-controlled and may be extended with equal weight to $I$. demorsa. Late in the course of the present study it 
became evident that males of both species exist in two behaviourtypes relative to mating preferences. These two behaviour-types appear to be genetically determined and functionally related to the two female colour morphs. The sex-controlled nature of the genes' expression may possibly occur in two ways producing two colour morphs in females and two behaviour-types in males. Studies are in progress to investigate this possibility.

The dimorphism's expression as two distinct classes and the segregation of both classes in the progeny of single females suggests a simple genetic basis. A single allelic autosomal gene pair is the straightforward hypothesis since 1 . damula's similar dimorphism appears to be inherited in that fashion. Adoption of this hypothesis requires that the one male phenotype include both homozygous classes, $h^{+} h^{+}$and $h h$, and

TABLE I

Mean daily duration for colour stages illustrated in fig. I and mean daily life under 24 hour illumination (850 lumen) for female morphs of Ischnura demorsa

\begin{tabular}{|c|c|c|c|c|c|}
\hline \multirow{2}{*}{$\begin{array}{l}\text { Morph and } \\
\text { condition }\end{array}$} & \multicolumn{3}{|c|}{ Colour phases } & \multirow{2}{*}{ Mean life } & \multirow{2}{*}{ Sample size } \\
\hline & I & 2 & 3 & & \\
\hline $\begin{array}{l}\text { Heteromorphic } \\
20^{\circ} \mathrm{C} \text {. } \\
29^{\circ} \mathrm{C} \text {. }\end{array}$ & $\begin{array}{l}5 \cdot 0 \\
2 \cdot 5\end{array}$ & $\begin{array}{l}4 \cdot 0 \\
3 \cdot 5\end{array}$ & $\begin{array}{l}5 \cdot 0 \\
4^{\cdot 0}\end{array}$ & $\begin{array}{l}14 \cdot 0 \\
11 \cdot 0\end{array}$ & $\begin{array}{r}9 \\
\text { I2 }\end{array}$ \\
\hline $\begin{array}{l}\text { Andromorphic } \\
20^{\circ} \mathrm{C} \text {. } \\
29^{\circ} \mathrm{C} \text {. }\end{array}$ & $\begin{array}{l}3.5 \\
1 \cdot 0\end{array}$ & $\begin{array}{l}4.5 \\
3.0\end{array}$ & $\begin{array}{l}6 \cdot 5 \\
4 \cdot 0\end{array}$ & $\begin{array}{r}14.5 \\
8 \cdot 0\end{array}$ & $\begin{array}{r}10 \\
7\end{array}$ \\
\hline
\end{tabular}

the heterozygotes, $h^{+} h$. Andromorphic females, assumed homozygous recessive, $h h$, could produce female offspring in $\mathrm{r}: \mathrm{r}, \mathrm{r}: 0$, and $0: \mathrm{I}$ ratios of dominant to recessive types. Heteromorphic females could produce female offspring in $3: \mathrm{r}, \mathrm{r}: \mathrm{r}$, and $\mathrm{r}: \mathrm{o}$ ratios of dominant to recessive types. The single genotype of andromorphic females may be judged at time of mating. Offspring ratios of $\mathrm{r}: 0$ and $0: \mathrm{r}$ for dominant to recessive types from crosses with andromorphic females should identify both homozygous classes in male parents. A 3:1 ratio of dominant to recessive types resulting from a cross involving the heteromorphic female parent should identify the $h^{+} h$ class in both the male and female parents. Crosses with a male of $h^{+} h$ or $h h$ genotypes (determined by multiple male matings) to heteromorphic females may identify the $h^{+} h^{+}$class in such females.

Breeding results are given in tables 2 and 3 . The observed segregation numbers of each cross were paired with the best agreeing expectation values available from the above hypothesis relative to the morph of the parental female. A chi-square analysis revealed no significant differences at the 95 per cent. level of confidence. Male 
number 7 was, however, crossed with two heteromorphic females and the data are not compatible with a common male genotype for both crosses. In view of the close agreement existing in other crosses, the

TABLE 2

Data for female offspring segregating from heteromorphic female parents. See text for origin of expected values

\begin{tabular}{|c|c|c|c|c|c|c|}
\hline \multirow{3}{*}{$\begin{array}{c}\text { Fertilised } \\
\text { by male }\end{array}$} & \multicolumn{6}{|c|}{ Female offspring } \\
\hline & \multirow{2}{*}{ No. } & \multirow{2}{*}{ Per cent. } & \multicolumn{2}{|c|}{ Per cent. heteromorphic } & \multicolumn{2}{|c|}{ Per cent, andromorphic } \\
\hline & & & Observed & (Expected) & Observed & (Expected) \\
\hline $\begin{array}{r}1 \\
2 \\
3 \\
4 \\
5 \\
6 \\
6 \\
7 \\
7 \\
8 \\
15 \\
16 \\
17 \\
18 \\
19\end{array}$ & $\begin{array}{l}38 \\
44 \\
46 \\
32 \\
39 \\
42 \\
29 \\
43 \\
27 \\
46 \\
35 \\
41 \\
31 \\
42 \\
33\end{array}$ & $\begin{array}{l}55 \cdot 8 \\
55 \cdot 7 \\
55 \cdot 4 \\
46 \cdot 4 \\
54 \cdot 9 \\
57 \cdot 6 \\
53 \cdot 7 \\
57 \cdot 3 \\
56 \cdot 3 \\
55 \cdot 4 \\
56 \cdot 4 \\
54 \cdot 0 \\
52 \cdot 6 \\
58 \cdot 3 \\
55 \cdot 9\end{array}$ & $\begin{array}{r}68 \cdot 4 \\
77 \cdot 3 \\
84 \cdot 8 \\
62 \cdot 5 \\
64 \cdot 2 \\
45 \cdot 3 \\
55 \cdot 3 \\
69 \cdot 7 \\
40 \cdot 7 \\
56 \cdot 5 \\
100 \cdot 0 \\
80 \cdot 5 \\
70 \cdot 9 \\
69 \cdot 0 \\
81 \cdot 8\end{array}$ & $\begin{array}{r}(75) \\
(75) \\
(75) \\
(75) \\
(75) \\
(50) \\
(50) \\
(75) \\
(50) \\
(50) \\
(100) \\
(75) \\
(75) \\
(75) \\
(75)\end{array}$ & $\begin{array}{r}31 \cdot 6 \\
22 \cdot 7 \\
15 \cdot 2 \\
37 \cdot 4 \\
35 \cdot 8 \\
54 \cdot 7 \\
44 \cdot 7 \\
30 \cdot 2 \\
59 \cdot 3 \\
43 \cdot 5 \\
0 \cdot 0 \\
19 \cdot 5 \\
29 \cdot 1 \\
31 \cdot 0 \\
18 \cdot 2\end{array}$ & $\begin{array}{l}(25) \\
(25) \\
(25) \\
(25) \\
(25) \\
(50) \\
(50) \\
(25) \\
(50) \\
(50) \\
(0) \\
(25) \\
(25) \\
(25) \\
(25)\end{array}$ \\
\hline
\end{tabular}

TABLE 3

Data for female offspring segregating from andromorphic female parents. See text for origin of expected values

\begin{tabular}{|c|c|c|c|c|c|c|}
\hline \multirow{3}{*}{$\begin{array}{c}\text { Fertilised } \\
\text { by male } \\
\text { no. }\end{array}$} & \multicolumn{6}{|c|}{ Female offspring } \\
\hline & \multirow{2}{*}{ No. } & \multirow{2}{*}{ Per cent. } & \multicolumn{2}{|c|}{ Per cent. heteromorphic } & \multicolumn{2}{|c|}{ Per cent. andromorphic } \\
\hline & & & Observed & (Expected) & Observed & (Expected) \\
\hline 10 & 32 & $54 \cdot 3$ & $53 \cdot \mathrm{I}$ & (50) & $46 \cdot 9$ & (50) \\
\hline II & 42 & $\begin{array}{r}57.6 \\
57.6\end{array}$ & $57 \cdot 1$ & (5o) & $42 \cdot 9$ & (50) \\
\hline 12 & 32 & $5^{1 \cdot 7}$ & $0 \cdot 0$ & (o) & $100 \cdot 0$ & (100) \\
\hline & 40 & $57 \cdot 2$ & $60 \cdot 0$ & $(50)$ & $4^{0} \cdot 0$ & $(50)$ \\
\hline 14 & 34 & 54.8 & $100 \cdot 0$ & (100) & $0 \cdot 0$ & (o) \\
\hline 15 & 37 & $56 \cdot 9$ & $0 \cdot 0$ & (o) & $100 \cdot 0$ & (100) \\
\hline 16 & $3^{8}$ & $53 \cdot 6$ & $57 \cdot 8$ & (50) & $4^{2 \cdot 2}$ & $(50)$ \\
\hline 20 & 40 & $54 \cdot 1$ & $60 \cdot 0$ & (5o) & $40 \cdot 0$ & (50) \\
\hline
\end{tabular}

ratio in the cross having only 27 offspring is assumed to reflect sampling error. That cross gave the smallest number of scorable offspring. The three male and two heteromorphic female genotypes expected under 
the hypothesis occur in the parents. Male number 14 is judged to be $h^{+} h^{+}$. The two crosses with male number 15 identifies the same class in a heteromorphic female. Males number 6, 8, 12, and 15 are judged to be $h$ in genotype and all crosses with $3: 1$ ratios would therefore have $h^{+} h$ genotypes in both parents. The three possible genotypes occurring in both male and female parents indicate that the gene loci are on the autosomes. The female percentages from total offspring per cross are also given in tables 2 and 3 . With one exception, females were slightly more numerous similar to the comparable data for I. damula (Johnson, $1964 a)$.

The phenotypic frequency $\left(q^{2}\right)$ of andromorphic females at the Bosque Del Apache National Wildlife Refuge has ranged between 0.34 and 0.38 over the study interval. Using the median $q^{2}$ value of $0.36, p$ and $q$ values of 0.4 and 0.6 exist as the gene frequencies of $h^{+}$and $h$ espectively. The expected frequency of $h^{+} h^{+}$individuals should therefore approximate a value of 0.16 in males and 0.25 in heteromorphic females as judged from the Hardy-Weinberg expression. Out of 19 and 15 randomly selected male and heteromorphic female parents respectively the $h^{+} h^{+}$appeared once for each sex. In fact, the number of crosses contributing to this study was extended more than planned in an effort to establish the existence of $h^{+} h^{+}$genotypes. The $h^{+} h^{+}$frequencies of 0.053 and 0.066 in males and heteromorphic females respectively are taken from small samples; however, they nonetheless suggest the presence of a heterozygous advantage. The random mating assumption required for the Hardy-Weinberg expression will require a closer examination as the factors affecting morph frequencies appear to be complex. The existence of two male behaviour-types in addition to the fact that the heteromorphic female is occasionally collected in tandem with males of other Ischnura species appear to be involved in the morphs' evolutionary significance.

\section{SUMMARY}

I. Females of $I$. demorsa are initially dimorphic in pattern and colour while all males express one phenotype. One female form, the andromorph, is initially similar to the male but distinct from the second female form, the heteromorph. The initial colour pattern of the latter morph is however similar to heteromorphic females of several other Ischnura species.

2. The initial patterns of both morphs develop shortly after emergence. Each morph subsequently undergoes a specific change in colour pattern culminating in a bluish-white patternless body colour for both morphs. Males retain their initial colour pattern throughout life.

3. The heritability of morphs in different environments is assumed to have negligible environmental component. The duration spent in each age-induced colour phase is however less at higher temperatures as is the total life. All colour phases occur in both mated and virgin females. 
4. The dimorphism is inherited through a single allelic autosomal gene pair having a sex-controlled expression. Andromorphic females are homozygous recessive and heteromorphic females are either homozygous dominant or heterozygous. Males possess all three genotypes.

Acknowledgment-This study was supported by National Science Foundation Grants 24126 and $355^{8}$.

\section{REFERENCES}

JOHNSON, CLIFroRD. 1964a. The inheritance of female dimorphism in the damselfly, Ischnura damula. Genetics, 49, 513-519.

Johnson, CLIFFord. 1964 $b$. Polymorphism in the damselflies, Enallagma civile (Hagen) and E. praevarum (Hagen). Amer. Midl. Nat., 72, 408-416.

JOHNSON, CLIFFORD. 1965. Mating and oviposition of damselfies in the laboratory Canadian Ent., 97, 321-326.

GRIEVE, E. G. 1937. Studies on the biology of the damselfly, Ischnura verticalis Say, with notes on certain parasites. Ent. Amer., 17, 12 1-153. 